\title{
The Prospects for the Implementation of School-Based Financial Management in Taiwan
}

\author{
Hsuan-fu Ho (Corresponding author) \\ Graduate School of Educational Administration and Policy Development \\ National Chiayi University, Chiayi, Taiwan \\ Tel: 886-922-910-101Ｅ-mail: hfho@mail.ncyu.edu.tw
}

\begin{abstract}
The current approach to solving educational problems in Taiwan is to adopt policies employed in Western countries. However, given the very different cultural and educational environment of Asia, not all policies effective in Western countries are necessarily applicable to schools in Taiwan. Therefore, an examination of the feasibility and applicability of these policies is essential. This study examines whether the school-based financial (SBF) management that is effective in Western countries is applicable to schools in Taiwan. Focus group interviews composed of government officials, scholars, principals, department directors, and teachers were conducted, and a questionnaire survey was administered to 1000 school personnel. The results indicate that the SBF model that is effective in the West is also applicable to schools in Taiwan, and that the Taiwanese government should adopt SBF, while adapting it to suit the local environment.
\end{abstract}

Keywords: School-based financial management, Taiwan, Decentralization

\section{Introduction}

Facing imminent defeat by Communist forces in the long-running Chinese Civil War, in 1949 the ROC government abandoned the Chinese mainland and retreated to the island of Taiwan. Afterwards, Taiwan was governed under martial law for nearly four decades, during which time its educational finance system was strictly and centrally controlled by the government, and up to the present almost no major improvements in school finance have been implemented. When marital law was finally lifted in 1987 there were widespread calls for educational decentralization. However, after such a long period of strict government control there was a serious lack of knowledge about school finance. Thus Taiwan's school finance system remains highly centralized and contains many serious problems.

First of all, since few MOE officials have any teaching experience, they tend to make resource allocation decisions which are not in accordance with the actual needs of local schools. Although some officials in the central government are knowledgeable about local schools, with so many schools in Taiwan, it is simply not possible to establish a unified budget formula that will fit all schools.

In order to apply its unified formula and prevent abuse of funds, the government spends considerable resources and manpower every year on supervising school financial activities. However, many principals still choose to risk their careers by breaking the rules in order to make more effective use of school funds. Moreover, due to the inflexibility of the current centralized financial system, certain financial exigencies may not get adequate attention in time.

It is widely believed that the current system is not efficient. Individual schools typically do their best to use up all their current funding, fearful that any surplus at the end of the year will result in budget cuts for the following year. Moreover, the wasting of public money has been worsened by a recently-enacted rule by which a principal will be punished if his or her school has a yearly budgetary surplus of more than $15 \%$.

Unfairness is another serious problem of the current system. Since special grants are determined by the government, and there are no objective standards for determining grant amounts and which schools will receive them, many have complained that the distribution process is based mostly on the relationship between the principal and the government officials, rather than on the school's performance or needs.

As a result, many scholars suggest that the current school finance system in Taiwan requires significant modifications to produce a system that more fairly and efficiently responds to fiscal and instructional goals. Moreover, since many of the financial problems schools are facing can be attributed to the current centralized control system, school-based management, which aims to shift decision-making authority and responsibility from the central to the local level, should be made an integral part of any future reform of the school finance system.

\section{Related Literature}

\subsection{Definition of school-based finance}

School-based finance (SBF) is one of the three main elements of the school-based management model, that is, 
school-based curriculum management, school-based personnel management, and school-based financial management. As such, SBF includes all of the decentralization concepts of school-based management. Malen, Ogawa, and Kranz (1990) defined school-based management as a formal alteration of governance structures which views the individual schools as the primary unit of improvement, and relies on the redistribution of decision-making authority as the primary mechanism to simulate and sustain improvements. Murphy and Beck (1995) argued that although there are many different definitions of school-based management, it invariably involves school-level autonomy and participatory decision-making.

Young (1995) divides a school's authority into three domains - budget, personnel and curriculum. Odden and Bush (1998) further argue that among these three school-based management domains, SBF management is of great importance, because providing schools with power over their budgets is a prerequisite for bolstering other decentralization reform efforts. However, many scholars have warned that SBF management alone does not improve academic achievement. Rather, only when a decentralized budget is accompanied by other school reforms will there be an increase in the quality of education (Brown, 1990; Thomas \& Martin, 1996; Cheng, 1996).

Odden and Picus (2004) summarized the essential elements of an effective SBF system as follows: (1) The government allocates most funding in a lump sum directly to schools; (2) How much money should be allocated to which school is decided by a set formula; (3) The local schools are given the decision-making authority and the responsibility for using the funds; (4) Any leftover funds may be carried over to the following years; and (5) The system is supervised by the general public.

\subsection{The merits of SBF}

The advocates of SBF argue that those people closest to students - parents, principals, teachers, and school directors - are more knowledgeable about student needs than are the staff in central government offices. Thus, redistributing the financial decision-making authority to local schools ensures that educational funds are spent in a way which is responsive to local needs. Moreover, since various social problems inevitably find their way into schools, schools should be given the authority and responsibility to flexibly and effectively solve such problems in a timely manner (Cheng, 1996; Odden \& Picus, 2004).

School-based management emphasizes participative decision making, and the involvement of stakeholders helps create a feeling of ownership which fosters the loyalty and dedication that are necessary for improving education. Moreover, allowing schools to carry over any budgetary leftovers at the end of the fiscal year helps ameliorate school resource abuse, and encourages schools to better use "their own money," which in turn further increases efficiency (Neal, 1991; Harter, 1999).

Using a student enrollment-based formula to calculate the funds for each school improves the fairness of resource allocation and, at the same time, ameliorates political interference. Finally, reviewing and auditing of school expenditures by the stakeholders improves the efficiency of resource allocation and reduces the government's auditing and supervision expenditures (Picus, 1997; Odden \& Picus, 2004).

\subsection{Problems with implementing SBF}

Neal (1991) warns that although SBF management has many merits, it is by no means perfect, and if it is not implemented properly the harm may be even greater than the benefit. He further suggests that the main reason why some schools fail to implement SBF is not that SBF per se is ineffective, but rather the presence of resistance at the central, district and/or school level. Sackney and Dibski (1994) also point out that sometimes policy makers want to appear to share authority without, in fact, surrendering authority.

Picus (1997) asserted that school personnel are often the main factor leading to failure, since some school teachers and principals are just not ready to take on the added responsibilities inherent in SBF. Thus, reforms can be rendered fruitless if the government is not willing to really devolve spending decisions to lower levels, or if school personnel are neither willing nor able to take on additional or new responsibilities. He further warns that if financial information is not sufficiently transparent, SBF can provide increased opportunities for the fraudulent use of educational funds.

Lavacic and Blover (1997) cautioned against the inefficient use of educational resources which could result if a school's personnel do not possess the knowledge and skills required to formulate a sound budget.

Finally, Senge (1990) and Fullen (1991) pointed out that when people try something new, it often takes some time before things get noticeably better, so it is critical that adequate supports are provided in case things get worse at the beginning. Odden and Picus (2004) warned that it takes a great deal of money to implement SBF due to scale, required staff training, and initial subsidies, and that an innovation is doomed to failure if the purpose of the change is mainly to save money or the changes are made too abruptly.

\section{Methodology}

The research began with an analysis of recent articles and documents in order to integrate the viewpoints of leading 
authors in the field regarding the merits, limitations, and implementation of SBF. Thereafter, focus group interviews consisting of government officials, principals, department directors, and school teachers were conducted to re-examine the information collected from the document analysis, and to add important information specific to the school environment in Taiwan.

The findings of the focus group interview identified 14 merits, 9 obstacles, and 13 skills directly relevant to the implementation of SBF, based on which a draft questionnaire was produced and used to obtain information about the opinions of school personnel.

A pre-test was then conducted to determine the reliability and validity of the questionnaire. The draft questionnaire was sent to 250 school personnel (principals, teachers, and accountants), and 226 were returned. Factor analysis was adopted for the validity test, and one question was dropped because its factor loading was only .246, which was much smaller than the acceptable cutoff value of .4. The deletion resulted in a KMO of .873 and a Barlett of .000 , and the total variance explained rate was $52.63 \%$.

Thereafter, Chronbach's $\alpha$ was adopted as the main method for testing the reliability of the questionnaire. With a Chronbach's $\alpha=.89$, the questions exhibited very high reliability!! Moreover, from the perspective of changes in Chronbach's $\alpha$ as a result of deleting a particular item, we found no deletion resulted in an increase in reliability, and thus kept all the questions for the formal questionnaire.

The formal questionnaire was delivered to 1000 school personnel in 100 elementary schools. The schools were selected at random from a list of 2,547 schools across Taiwan published by the Taiwan Ministry of Education. We asked each of the chosen schools to administer the questionnaire to one principal, one accountant, three department directors, and five teachers. Only responses received within one month of the initial mailing were included in the study. Of the 793 questionnaires returned within one month, 750 were valid for the analyses.

\section{Research Results}

The questionnaire was used to assess perceptions of school personnel regarding the adoption of SBF, and to determine the correlation between their demographic characteristics and their perceptions of the merits, obstacles, and skills relating to the implementation of SBF.

\subsection{The merits of SBF}

The results of the questionnaire identified several major merits of SBF as perceived by school personnel, and their relative importance was ranked. School personnel were asked to respond to the questions on a five-point Likert Scale, with a score of 5 indicating total agreement, and a score of 1 indicating total disagreement. All the merits were given very high scores in the test, with a high of 4.39 for the expectation that SBF will be effective in alleviating the common wasting of educational funds at the end of each year, to a low of 3.99 for the expectation that SBF will help teachers use school funds more effectively and efficiently.

One-way ANOVA (analysis of variance) revealed that the mean merit ratings differed significantly between different positions. Specifically, the mean merit ratings of principals and directors were significantly higher than those of school accountants and teachers (see Table 1).

The interview findings were mostly consistent with the survey results. Almost all interviewees expressed agreement with the merits listed in the questionnaire, and principals tended to be the most supportive of the implementation of SBF, despite knowing that the implementation of SBF may well increase their work loads. This result is also consistent with studies carried out in the West, such as Brown's (1990) study which found that although school personnel were aware of the possible challenges and obstacles relating to school-based management, they were in favor of the new system because they found it enhanced their self-esteem and increased their job satisfaction.

Moreover, as Murphy and Beck (1996) found, principals play the most important role in the implementation of SBF reforms. Thus it was not surprising that among all school personnel, principals gave the highest ratings to the merits of SBF, and that their support is essential to the success of SBF reforms.

\subsection{Obstacles to the implementation of SBF}

School personnel were also asked to rate the possible obstacles to implementing SBF, and the results indicated the existence of several major barriers. First of all, almost all teachers expressed concern about the widening financial inequity between schools located in the city and those located in suburban and rural areas. This is because the implementation of an SBF system would allow schools to generate funds through parental donations or corporate sponsorships, and, since parents living in Taiwan's urban areas tend to be much more well off than their suburban and rural counterparts, this would result in urban schools receiving much more supplementary funding than suburban and rural schools.

Further, the data suggests that school personnel are skeptical regarding the government's willingness to truly surrender 
financial authority to schools. Many interviewees pointed out that grants are the major tool used by the government to control schools, and can also be used to bring into line schools that do not fully obey government rules. Thus, they reason, it is almost impossible for the government to really shift the authority and responsibility for financial decision-making to schools. As a result, many school personnel see SBF as merely a fancy catch phrase used by the government to fool them into thinking that they have more authority than they actually do, or as just another soon-to-be-forgotten reform fad.

The third-strongest concern was that businesses such as textbook companies might shift their marketing focus from the government to the schools, thereby increasing business interference in schools. Such problems are particularly serious in large cities because there are many more businesses around the schools, and it is more lucrative for them to interfere in the procurement decisions of city schools.

The ANOVA analyses of the ratings of the obstacles to SBF indicated significant differences according to the respondent's position in the school, with principals rating the obstacles significantly lower than accountants and teachers. However, the mean rating of obstacles by principals did not differ significantly from that of department directors.

Once again, many scholars claim that principals are the key to success of SBF reforms, and the results show that among all school personnel, principals assign the highest scores to the merits of SBF, and the lowest scores to the obstacles. This enthusiasm for SBF on the part of principals indicates good prospects for the implementation of SBF in Taiwan.

\subsection{Knowledge required for the implementation of $S B F$}

What knowledge and skills are required for SBF to work effectively? Since there is little information available in this area, one of the main purposes of the focus group interviews described above was to identify the knowledge and skills required for the effective implementation of $\mathrm{SBF}$.

The results of the interviews indicate that in order to form a sound school-based budget, practical knowledge must be developed for handling cash flow, risk management, interschool competition for resources, and differing student needs. Moreover, school personnel have to possess the interpersonal and communication skills necessary for effectively dealing with competition between departments for scarce resources and factionalism among school personnel—-two issues which constitute major barriers to formulating a sound budget. Sound budgeting also requires adequate knowledge of the relevant laws and regulations. Finally, school personnel have to possess knowledge and skills in the area of information collection and distribution, because SBF management requires complete disclosure of budgeting information to ensure that the budget is spent wisely, and to avoid misappropriation of funds.

A questionnaire was produced based on the findings of these interviews and administered to the school personnel. First of all, it was surprising that, overall, school personnel indicated that they already possess sufficient knowledge and skills in almost all the areas relevant to the implementation of SBF. They indicated relatively more confidence in their knowledge regarding general communication, policy making, and the needs of different students, but less confidence in the areas of budget development, risk management, accounting, auditing, and legalities.

As with the obstacles to SBF, the knowledge possessed by participants differed significantly depending on their position. The results of post hoc analysis for variables examined by ANOVA showed that the mean knowledge rating for principals was significantly higher than that for all other school personnel, and the rating for school accountants was significantly higher than that for teachers and department directors.

\section{Conclusions and Implications}

Because educational resources have been tightly and centrally controlled by the ROC government since 1949, and only meager reforms have been conducted over the past two decades, Taiwan's school finance system has become obsolete and counterproductive. SBF management, which has proven to be effective in the West, seems to be a promising approach to addressing this problem. However, given the very different educational environment, policies effective in Western countries are not necessarily applicable to schools in Taiwan. Therefore it is essential to make a thorough examination of the feasibility and applicability of any models adopted from overseas.

School personnel were asked to rate their agreement with each merit of SBF on a scale of 1 to 5, and the very high average score of 4.22 indicates that school personnel in Taiwan strongly believe that SBF will tremendously enhance the efficiency of school finance, which, in turn, will contribute to their willingness to support the implementation of SBF.

Another finding which supports the feasibility of adopting SBF is that most respondents indicated that they were prepared to implement it, claiming that they already possess the necessary knowledge and skills. This result differs from Western theories and studies which claim that school personnel lack SBF knowledge and skills, and therefore need to be properly trained before they can successfully implement it. This difference may be due to differences in school programs and structures. In Taiwan, the school principal and the director of the department of general affairs are 
responsible for such school finance issues as procurement, maintenance, and construction. In the West, however, these duties are generally assigned to the district superintendents and school business administrators. Since school personnel in Taiwan already possess some of the knowledge required for SBF management, it is therefore likely that the adoption of SBF in Taiwan is feasible.

It is also important to realize that in Taiwan principals support SBF more than any other school personnel. The principals strongly agree with all the merits of SBF, and they see the obstacles as less serious. Also, they tend to be more confident than any other school personnel in regards to the knowledge and skills required to successfully implement SBF management. This phenomenon is advantageous to the implementation of SBF because principals play a key role in the success of SBF management, and they shoulder the primary responsibilities for resource allocation. This further strengthens the feasibility of adopting SBF management in Taiwan.

Although school personnel express support and enthusiasm for the implementation of SBF, they also have concerns about various obstacles relating to the implementation of SBF management. The respondents were especially worried about the potential for widening the equity gap between schools located in different geographic areas, and they also expressed skepticism toward the government's willingness to really surrender its authority over resource allocation and decision-making. However, these obstacles are similar to those encountered in the West, and Taiwan can learn from the experience of Western countries in addressing these problems.

Finally, the results of this study indicate that in Taiwan almost all the merits, obstacles, and required knowledge relating to SBF are consistent with the theories and experiences of SBF management in the West. This indicates that the SBF theories developed in the West are largely applicable to schools in Taiwan, and that Taiwan can adopt and adapt the SBF model to serve local needs. The successful adoption of SBF in Taiwan will require giving schools more freedom to formulate their own budgets, establishing a formula to ensure that an appropriate amount of funding is going directly to schools, improving the auditing system, making school budget information more transparent, and assigning responsibilities to school members.

\section{References}

Brown, D. J. (1990). Decentralization and school based management. New York: The Falmer Press.

Cheng, Y. C. (1996). School effectiveness and school based management:

a mechanism for development. Washington, D. C.: The Falmer Press.

Fullen, M. G. (1991). The new meaning of educational change $\left(2^{\text {nd }}\right.$ ed.). New York, NY: Teachers College Press.

Harter, E. A. (1999). How educational expenditures relate to student achievement: Insights from Texas elementary schools. Journal of Education Finance, 24(3), 281-302.

Levacic, R. \& Glover, D. (1997). Value for money as a school improvement strategy: Evidence from the new inspection system in England. School Effectiveness and School Improvement, 8(2), 231-253.

Malen, B., Ogawa, R. T. \& Kranz, J. (1990). What do we know about school-based management? A case study of the literature - a call for research. In W. H. Clune, \& J. F. Witte (Eds.), Politics of excellence and choice in education. Philadelphia, PA: The Falmer Press.

Murphy, J. \& Beck, L. G. (1995). School-based management as school reform: Taking stock. Thousand Oaks, CA: Corwin Press.

Murphy, J. \& Beck, L. G. (1996). The four imperatives of a successful school. Thousand Oaks, CA: Corwin Press.

Neal, R. G. (1991). School based management: A detailed guide for successful implementation. Bloomington, IN: National Education Services.

Odden, A. R. \& Busch, C. (1998). Financing schools for high performance. San Francisco: Jossey-Bass Publishers.

Odden, A. R. and Picus, L. O. (2004). School finance: A policy perspective. New York: McGraw-Hill.

Picus, L. O. (1997). Assigning responsibilities: Where do the dollars go? School Business Affairs, 63(11), 8-15.

Sackney, L. E. \& Dibski, D. J. (1994). School-based management: A critical perspective. Educational Management and Administration, 22(2), 104-112.

Senge, P. M. (1990). The fifth discipline: The arts and practice of the learning organization. New York: Currency Doubleday.

Thomas, H. \& Martin, J. (1996). Managing resources for school improvement. New York: Routledge.

Young, R. L. (1995). What is the most effective structure? Site-based budgeting is best. School Business Affairs, 6(6), $38-42$. 
Table 1. ANOVA of the merits of SBF according to position

\begin{tabular}{llllllll}
\hline Position & N & M & Source V & SS & MS & F & Sheffé \\
\hline (1) Principal & 76 & 4.48 & Between & 19.40 & 6.47 & $27.76^{* * *}$ & $(1)>(2)$ \\
(2) Accountant & 63 & 4.10 & Within & 173.73 & 0.23 & & $(1)>(4)$ \\
(3) Director & 336 & 4.33 & Total & 193.13 & & $(3)>(2)$ \\
(4) Teacher & 275 & 4.04 & & & & $(3)>(4)$ \\
\hline
\end{tabular}

$* * * \mathrm{P}<.001$

Table 2. ANOVA of the obstacles to the implementation of SBF according to position

\begin{tabular}{llllllll}
\hline Position & N & M & Source V & SS & MS & F & Sheffé \\
\hline (1) Principal & 76 & 3.13 & Between & 5.80 & 1.94 & $4.97^{*}$ & $(1)<(2)$ \\
(2) Accountant & 63 & 3.44 & Within & 290.28 & 0.39 & & $(1)<(4)$ \\
(3) Director & 336 & 3.33 & Total & 296.08 & & & \\
(4) Teacher & 275 & 3.42 & & & & & \\
\hline
\end{tabular}

$* \mathrm{P}<.05$

Table 3. ANOVA of the knowledge required for the implementation of SBF according to position

\begin{tabular}{llllllll}
\hline Position & N & M & Source V & SS & MS & F & Sheffé \\
\hline (1) Principal & 76 & 4.16 & Between & 125.84 & 42.0 & $92.07 * * *$ & $(1)>(2)$ \\
(2) Accountant & 63 & 3.78 & Within & 339.87 & 0.46 & & $>(3)>(4)$ \\
(3) Director & 336 & 3.44 & Total & 465.71 & & & \\
(4) Teacher & 275 & 2.88 & & & & & \\
\hline
\end{tabular}

$* \mathrm{P}<.001$ 